\title{
Challenges for a Global Family Sociology
}

\author{
Introductory Essay for the Japanese Journal of Family Sociology
}

\section{Rudolf Richter}

Globalization is often said to result in uniformity: uniformity in production, uniformity in consumption, uniformity in urbanization, uniformity in modernization, uniformity in behavior, and uniformity in science. Does 'one science' mean one paradigm, one theory, and one method? Does it allow us to encompass empirical diversity? Do we aim for one global family sociology?

Hardly anyone will doubt that the scientific standards of objectivity, of thorough and systematic observation, of validity and reliability are core elements of sociological research. One can send a paper written in English to reviewers worldwide and generally find that they will agree on the quality of the paper so long as they are working in the same field of research and paradigm and paying respect to others.

On the other hand, not all methods are applicable in all societies. As we agree to have questionnaires as a measuring instrument worldwide, there might be cultural differences concerning what you can ask. Even the simple question "Is family important to you?" will have different meaning in different cultures, depending on the definition of "family." Even within Europe, where I come from, you will find a different understanding of family in the northern Scandinavian countries (more individualistic, family members as friends) from that in the south (more collective referring to the extended family and concentrating very much on the patriarchal system). More differences will appear worldwide. Would you say the Japanese family and its traditions are similar to those in Europe? In what way?

The theory of modernity is often the reference point in international comparisons in family research. Trends to lower fertility rates, higher age of marriage, better educated women, combining work and family life, and the core family is seen as global trends. Though on a large scale you might find evidence for that direction, how are people living these trends locally? Are they acting in a modern way when they postpone marriage - or are other causes responsible for that? And is it not that such a theory has normative power rather than empirical evidence?

Let me give an example from various contributions in the Handbook of World Families, edited by Adam and Trost (2005). Authors from different countries all over the world report on dating, marrying, and separation. Though everywhere these processes occur, how they are performed looks very different. In Kenya, early sexual intercourse without marriage prevails and women might have lovers but are not expected to marry them: in Kuwait or Egypt, Muslim ethics predominate and sexual

Rudolf Richter: Professor, Department of Sociology, University of Vienna

President of Research Committee on Family Research (RC06), International Sociological Association

E-mail: rudolf.richter@univie.ac.at 
intercourse for women is bound to marriage: in India, the practice of arranged marriage is common: while in central Europe, the vision of romantic love exists. That is just to give a few examples. The more you go into detail, the more diversity appears. What does it help to know that worldwide there is a dating process and that this is a universality in human behavior, though we do not know how this process works?

It is still a fundamental challenge in family sociology to operate with diversities behind the general trends-with the result that we discover more possibilities of social change than a theory of modernization might suggest. Let me take and analogy from biology: it is not very impressive to state that everywhere grass is growing. Rather you want to know which kind of grass and which soil produces which kind of grass. To fulfill that task of thoroughly analyzing social phenomena and processes, we need both large, worldwide datasets that allow us to compare countries on specific indicators, and thorough local, historically informed empirical case studies that enable us to see how social processes in family relations work. It is less the social phenomena of "the family" which is under observation, but rather the social processes that bring it to life.

The plea for this diversity has another implication. The scientific reporting system is in English, though local cultures have their own specific languages. While it is an enormous advantage in scientific communication to have a common scientific language, local experiences are often better expressed in local languages. At the same time as strengthening English as a scientific language, for instance, for teaching at least part of the courses in universities, we should also fight for money for translations. Beside a general research program, a global translation program will thoroughly enrich scientific knowledge.

Literature quoted:

Adams, B. and J. Trost, eds., 2005, Handbook of World Families, Thousand Oakes: Sage. 